\title{
High-restrained eaters only overeat when they are also impulsive
}

Citation for published version (APA):

Jansen, A. T. M., Nederkoorn, C., van Baak, L., Keirse, C., Guerrieri, R., \& Havermans, R. C. (2009). High-restrained eaters only overeat when they are also impulsive. Behaviour Research and Therapy, 47(2), 105-110. https://doi.org/10.1016/j.brat.2008.10.016

Document status and date:

Published: 01/01/2009

DOI:

10.1016/j.brat.2008.10.016

Document Version:

Publisher's PDF, also known as Version of record

Document license:

Taverne

Please check the document version of this publication:

- A submitted manuscript is the version of the article upon submission and before peer-review. There can be important differences between the submitted version and the official published version of record.

People interested in the research are advised to contact the author for the final version of the publication, or visit the DOI to the publisher's website.

- The final author version and the galley proof are versions of the publication after peer review.

- The final published version features the final layout of the paper including the volume, issue and page numbers.

Link to publication

\footnotetext{
General rights rights.

- You may freely distribute the URL identifying the publication in the public portal. please follow below link for the End User Agreement:

www.umlib.nl/taverne-license

Take down policy

If you believe that this document breaches copyright please contact us at:

repository@maastrichtuniversity.nl

providing details and we will investigate your claim.
}

Copyright and moral rights for the publications made accessible in the public portal are retained by the authors and/or other copyright owners and it is a condition of accessing publications that users recognise and abide by the legal requirements associated with these

- Users may download and print one copy of any publication from the public portal for the purpose of private study or research.

- You may not further distribute the material or use it for any profit-making activity or commercial gain

If the publication is distributed under the terms of Article $25 \mathrm{fa}$ of the Dutch Copyright Act, indicated by the "Taverne" license above, 


\title{
High-restrained eaters only overeat when they are also impulsive
}

\author{
Anita Jansen*, Chantal Nederkoorn, Lydia van Baak, Catharine Keirse, Ramona Guerrieri, \\ Remco Havermans
}

Department of Clinical Psychological Science, Faculty of Psychology, Maastricht University, P.O. Box 616, 6200 MD Maastricht, The Netherlands

\section{A R T I C L E I N F O}

\section{Article history:}

Received 13 April 2008

Received in revised form

28 August 2008

Accepted 17 October 2008

\section{Keywords:}

Restrained eating

Dieting

Impulsivity

Disinhibition

Obesity

Eating disorders

Restraint

Preload

\begin{abstract}
A B S T R A C T
Recent work shows that the inability to inhibit basic motor responses (like pressing a button) is related to overeating, weight gain and overweight. In the present study it was tested whether this inability to inhibit motor responses - or impulsivity - can differentiate between successful and unsuccessful restrained eaters. A typical preload and food exposure paradigm was used and it was hypothesized that only the high-restrained eaters that are simultaneously inefficient inhibitors of prepotent motor responses would overeat when confronted with tempting foods. In line with the hypothesis, the data show that overeating follows from an interaction between restraint and impulsivity; high-restrained eaters only overate when they were also impulsive. It is concluded that being restrained per se is not a determinant of overeating. Being a restrained eater only bears the risk of overeating in case of coexisting impulsivity.
\end{abstract}

(c) 2008 Elsevier Ltd. All rights reserved.

\section{Introduction}

Recent work shows that a basic inability to inhibit motor responses influences eating behavior and body weight. In a large series of experiments, Nederkoorn, Guerrieri and co-workers showed that less efficient response inhibition, or impulsivity, is related to increased intentions to diet (Nederkoorn, van Eys, \& Jansen, 2004), increased food intake and overeating (Guerrieri, Nederkoorn \& Jansen, 2007; Guerrieri, Nederkoorn, Stankiewicz, et al., 2007), increased weight and obesity (Guerrieri, Nederkoorn, \& Jansen, 2008; Guerrieri, Nederkoorn, Stankiewicz, et al., 2007; Nederkoorn, Braet, van Eijs, Tanghe, \& Jansen, 2006; Nederkoorn, Guerrieri, Roefs, \& Jansen, 2008; Nederkoorn, Smulders, Havermans, Roefs, \& Jansen, 2006) and less weight loss during weight reduction treatment (Nederkoorn, Jansen, Mulkens, \& Jansen, 2007).

These findings are particularly interesting because the impulsivity that was measured in these studies is a general behavioral trait that is essentially unrelated to eating behavior. The authors measured impulsivity in a basic behavioral task that assesses one's ability to inhibit prepotent motor responses, i.e. pressing a button. Participants are instructed to press a button as quickly as possible

\footnotetext{
* Corresponding author. Tel.: +31 43388 1908; fax: +31 433884196.

E-mail address: a.jansen@psychology.unimaas.nl (A. Jansen).
}

when they see a stimulus on a computer screen, but not to push when they hear a tone. In $75 \%$ of the trials participants are required to press the corresponding button, making this response the dominant or prepotent response. In $25 \%$ of the trials a stop signal (tone) follows shortly after the stimulus on the screen, signaling that participants should attempt to inhibit the prepotent response of pushing the corresponding button. In this way the stop-signal task assesses one's ability to inhibit prepotent motor responses, and being less able to inhibit these responses is considered a sign of increased impulsivity. It might be quite obvious to demonstrate that high scorers on scales measuring eating disinhibition overeat after a food challenge, but it is not at all self-evident to demonstrate that individuals who are unable to inhibit basic motor responses, like pressing a button, overeat.

By inducing impulsivity in high- and low-restrained eaters, Guerrieri and Nederkoorn demonstrated that impulsivity is not only associated with but also causally connected to overeating (Guerrieri, Nederkoorn, Schrooten, Martijn, \& Jansen, 2008; Guerrieri, Nederkoorn, Stankiewicz, et al., 2007). The induction of impulsivity showed a significant interaction with restraint status; the more restrained the participants were, the more sensitive they were to the impulsivity priming and the more calories they ingested after impulsivity was induced. These data suggest that increased impulsivity primarily leads to disinhibition in the behavioral domain(s) that people try to control. High-restrained 
eaters try to control their food intake, and when they are also high impulsive, they will be increasingly vulnerable to overeating when they are led into temptation. This reasoning might imply that highrestrained eaters who are not especially impulsive will be less vulnerable to overeating. There is some circumstantial evidence that supports this reasoning; a number of laboratory studies indeed show overeating of high-restrained eaters after the consumption of a preload or just mere exposure to tasty foods (Fedoroff, Polivy, \& Herman, 1997; Jansen \& van den Hout, 1991; Rogers \& Hill, 1989) but other studies show that high-restrained eaters do not always counter-regulate or overeat (see e.g., Dritschel, Cooper, \& Charnock, 1993; Jansen, Oosterlaan, Merckelbach, \& van den Hout, 1988; Jansen et al., 2003; Nederkoorn \& Jansen, 2002; Stice, Fisher, \& Lowe, 2004; Wardle \& Beales, 1987). Could it be that these mixed results are due to a variation in impulsivity levels of the highrestrained eaters? The high-restrained eaters that do not show overeating might be the individuals that are basically low impulsive.

To sum up, ingesting a tasty preload, or being exposed to the smell of tasty foods, usually triggers a prepotent response to eat, particularly in people that are sensitive to tasty foods and vulnerable to overeating, like high-restrained eaters. Highrestrained eaters by definition try to restrict their food intake, but not all of them succeed in refraining from eating when led into temptation (Stice et al., 2004). It is hypothesized that the success of one's attempt to restrain food intake is related to one's ability to inhibit prepotent responses, in other words, one's impulsivity. In particular the high-restrained eaters who are unsuccessful at inhibiting prepotent responses are expected to overeat in tempting situations. In the present study it is hypothesized that these high-impulsive high-restrained eaters eat more than lowimpulsive high-restrained eaters after being led into temptation in a typical preload and food exposure paradigm. It is expected that it is the interaction between restraint and impulsivity that is related to overeating: only the participants that are both high in restraint and in impulsive behavior in the form of less efficient response inhibition will overeat after a preload and after food exposure. Participants that are high restrained but low impulsive might be more successful in their restraint and it is therefore expected that they consume fewer calories than low-restrained eaters, also after a challenge. No differences in food intake are expected between the low-restrained high-impulsive participants and the low-restrained low-impulsive participants, because of their lack of food sensitivity.

\section{Method}

\section{Design and statistical analysis}

The dependent variable food intake was assessed after three different manipulations: ingesting a preload, smelling tasty food (exposure) and a control manipulation during which participants completed a questionnaire. A mixed design was used; condition being a within-subjects variable and the participant characteristics restraint and impulsivity being between-subjects variables. All participants participated in all three conditions in a counterbalanced order. They were divided in groups along the dimensions restraint (high/low) and impulsivity (high/low). The hypothesis was tested in a 3 (condition: preload vs. exposure vs. control) $\times 2$ (restraint: high vs. low) $\times 2$ (impulsivity: high vs. low) repeated measures ANOVA, with order of conditions as covariate and total caloric intake as the dependent variable, and followed by one-way ANOVAs with planned contrasts. Pearson P-M correlations between food intake, restraint and impulsivity in each of the conditions were also examined.

\section{Participants}

First year female college students (psychology and health sciences at Maastricht University, the Netherlands) were invited to participate in an experiment that was announced as a study into the influence of smell and taste on reaction time. Exclusion criteria were: age below 17 or above 25, and BMI below 17 or above 30. Of the 68 female students that applied 4 had a BMI below 17 or above 30 and were excluded from analysis. One participant's error rate for the stop-signal task was too high; this participant was also excluded. The remaining 63 female participants had a mean age of $19.1(\mathrm{SD}=1.3)$ and a mean body mass index $\left(\mathrm{BMI}=\mathrm{kg} / \mathrm{m}^{2}\right)$ of 22.4 $(\mathrm{SD}=2.6)$.

\section{Assessment}

\section{Eating restraint}

A Dutch translation of the restraint scale (RS; Herman \& Polivy, 1980) was used to measure eating restraint. The RS is a self-report questionnaire consisting of 10 items assessing concern for dieting and weight fluctuations. The RS is not a valid measure of acute caloric restriction but identifies individuals who have difficulty controlling their food intake under a variety of conditions (Stice et al., 2004; Stice, Presnell, Lowe, \& Burton, 2006; Williamson et al., 2007). Higher scores indicate increased difficulty to restrict food intake.

\section{Impulsivity}

The stop-signal task (SST; Logan, Schachar, \& Tannock, 1997) was used as a measure of impulsivity, defined as a decreased ability to inhibit prepotent responses. The SST consists of GO and STOP trials. During the go-trials, the letter $\mathrm{O}$ or the letter $\mathrm{X}$ is presented for $1000 \mathrm{~ms}$ on the centre of a computer screen, preceded by a $500 \mathrm{~ms}$ fixation point, also in the centre of the screen. The participant learns to press the button on the right side with the right hand when the $X$ is presented and the button on the left side and with the left hand when the $O$ is presented. The instruction during this choice reaction time task is to press the button as fast as possible. A crucial element of the task is that this learned response has to be inhibited during stop trials. During stop trials a stop signal, a computer-produced $100 \mathrm{~ms} 1000 \mathrm{~Hz}$ tone, is presented. The participant is instructed not to respond when she hears the tone. Between trials, the screen is blank for $1000 \mathrm{~ms}$. Initially, the delay between the go signal ( $\mathrm{X}$ or $\mathrm{O}$ ) and the stop signal is $250 \mathrm{~ms}$. Depending on the responding of the participant, a tracking procedure adapts the go-stop delay dynamically; if the participant succeeds in inhibiting the response, the go-stop delay is increased by $50 \mathrm{~ms}$, thereby making it more difficult to inhibit the next trial. If the participant fails to inhibit the response, the go-stop delay is decreased by $50 \mathrm{~ms}$, thereby making it easier to inhibit the next trial. The SST is designed to enable participants to inhibit $50 \%$ of the stop trials. The mean percentage of trials that was inhibited in the present study was 51.6 ( $\mathrm{SD}=4.4$ ), close to the ideal of $50 \%$, indicating that the task was executed well by the participants. The task consists of five blocks; the first block contains 64 trials and the other four blocks each contains 128 trials. There were an equal number of Xs and Os in a block and stop signals were presented on $25 \%$ of the trials, balanced over X and O trials. The order of trials was randomised. Between the blocks, the participant was allowed to take a break of $2 \mathrm{~min}$. The two variables of interest are reaction time (RT) and stop delay. The dependent variable stop signal reaction time (SSRT) is calculated by subtracting the stop delay from the reaction time. Longer SSRTs indicate poorer response inhibition, which is considered to reflect increased impulsivity.

In eating-related research the use of the stop-signal task (SST) is relatively new, but in attention-deficit/hyperactivity disorder 
$(\mathrm{AD} / \mathrm{HD})$ research the SST is a widely used measure of inefficient response inhibition (see e.g., Barkley, 1997). In this research area validity of the SST has been investigated. Nichols \& Waschbusch (2004) have reviewed studies testing the validity of the SST and other cognitive tasks to assess symptoms of $\mathrm{AD} / \mathrm{HD}$ and they conclude that the SST is among the tasks with the highest convergent, discriminant and predictive validity.

\section{Food intake and overeating}

Food intake was measured during a bogus taste test. Participants were presented with 6 bowls brimful with tasty high-caloric foods: $\pm 600 \mathrm{~g}$ of soft sweet licorice $(320 \mathrm{kcal} / 100 \mathrm{~g}), \pm 200 \mathrm{~g}$ of marshmallows ( $325 \mathrm{kcal} / 100 \mathrm{~g}), \pm 550 \mathrm{~g}$ of salted peanuts $(650 \mathrm{kcal} /$ $100 \mathrm{~g}), \pm 150 \mathrm{~g}$ of chips (550 kcal/100 g), $\pm 500 \mathrm{~g}$ of mini snickers (498 kcal/100 g), and $\pm 400 \mathrm{~g}$ mini milky ways (447 kcal/100 g). All the food was presented unwrapped and in small pieces to facilitate eating. Overeating is defined as a calorie intake that is significantly larger than the calorie intake in the low-restrained low-impulsive group, which is considered to be a group of normal eaters.

\section{Manipulations}

\section{Preload}

The preload consisted of two milkshakes, one vanilla and one chocolate flavoured. The chocolate milkshake was prepared with chocolate ice cream, chocolate milk and whipping cream; the vanilla milkshake was prepared of vanilla ice cream, milk, vanilla sugar and whipping cream. The participants were presented with $2 \times 125 \mathrm{ml}$ milkshakes ( $125 \mathrm{ml}$ of each taste), providing a total of $280 \mathrm{kcal}$ ( $120 \mathrm{kcal}$ for the vanilla and $160 \mathrm{kcal}$ for the chocolate milkshake). They were instructed to drink it all within $10 \mathrm{~min}$.

\section{Exposure}

Participants were exposed to the smell of the high-caloric foods that were also presented during the taste test. The exposure lasted 10 min during which the participant was instructed to take a piece of food to her nose, to keep it just under the nose, and to smell it intensely, following the food exposure procedure of Jansen (Jansen \& van den Hout, 1991; Jansen, 1998; Jansen et al., 2003). The experimenter modeled the exposure to ensure that all food items were smelled intensely and alternately, and that the participant did not eat the food.

\section{Control condition}

Participants in the control condition completed a Dutch translation of Zuckerman's Sensation Seeking Questionnaire (Feij \& van Zuilen, 1984; Zuckerman, 1994) during $10 \mathrm{~min}$. This questionnaire was used as time filler and considered to be irrelevant for the purpose of this experiment.

\section{Procedure}

The experiment ran between 1 and $6 \mathrm{pm}$ on weekdays, and each participant returned to the laboratory three times, always on the same day of the week and at the same time of day, with one week between the sessions. Participants were instructed to refrain from eating for a period of $2 \mathrm{~h}$ before the start of the experiment. After entering the laboratory, cell phones and other individual items were put away in another room, and it was once again explained to the participant that she took part in a study on the influence of tasting and smelling on reaction times. Then one of three manipulations started (the order was counterbalanced) and took place for 10 min. Immediately after the manipulation, the taste test started. The six preweighed bowls with food were placed in front of the participant. She was instructed to taste all the foods and to complete a taste perception questionnaire. It was stressed that she could eat as much as she liked or needed in order to complete the questionnaire. She was also told to wait in the lab for the experimenter to come back. After 10 min the experimenter returned and took the participant to another room were she completed the stopsignal task (session 1), or the restraint scale (session 3). The stopsignal task and restraint scale were administered at separate sessions to distribute the measurements evenly over the sessions. They were completed after both the manipulation and taste test were finished, to prevent an influence of performing the stopsignal task and completing the restraint scale on the experimental manipulations and taste test. An earlier study in our lab showed that performing the stop-signal task might influence impulsivity levels (Guerrieri, Nederkoorn, Schrooten, et al., 2008). Completing the restraint scale might also prime or sensitize participants, making them suspicious about the actual goal of the experiment and possibly influencing their eating behavior. It is also possible that exposure to the restraint scale prior to food intake might make high-restrained participants pursue more restraint than they would otherwise. Therefore, the restraint scale was always administered after the final taste test, that is, when the actual experiment was finished.

During the completion of the stop-signal task or the restraint scale, a second experimenter reweighed the remaining food and the amount of grams eaten of every food item was converted into kilocalories. After the third session, the participant was weighed and measured, and received $€ 25$ for participation in all three sessions. After the whole experiment was finished, participants were debriefed by e-mail. The Ethical Committee of the Psychology Faculty of Maastricht University approved the study.

\section{Results}

The participants were divided in a high- and low-restraint group, based on a European RS cut-off score of 13 (Jansen, Louwerse, Leemans, \& Schouten, 1998; Wardle, 1986), and in a highand low-impulsive group, based on the SSRT median-split (171.2). Group characteristics are given in Table 1.

Hypotheses: (a) participants that are both high restrained and high impulsive (HR-HI) will overeat after a preload and after food exposure compared to a control condition, whereas (b) participants that are high restrained and low impulsive (HR-LI) will eat less after a preload and after food exposure compared to a control condition, and (c) no differences in food intake are expected between the low-restrained high-impulsive participants (LR-HI) and the low-restrained lowimpulsive (LR-LI) participants.

The 3 (condition: preload vs. exposure vs. control) $\times 2$ (restraint: high vs. low) $\times 2$ (impulsivity: high vs. low) repeated measures ANOVA showed a significant Condition $\times$ Restraint $\times$ Impulsivity interaction, $F(2,57)=3.7, p=0.03$, qualifying a near to significant Restraint $\times$ Impulsivity interaction, $F(1,58)=3.9, p=0.052$. Additional one-way repeated measures ANOVAs with condition as the repeated measures factor and caloric intake as the dependent

\section{Table 1}

Group characteristics, mean (standard deviation). BMI $=$ Body Mass Index $=\mathrm{kg} / \mathrm{m}^{2}$, $\mathrm{RS}=$ restraint scale score, $\mathrm{SSRT}=$ stop-signal reaction time.

\begin{tabular}{|c|c|c|c|c|c|}
\hline & $\begin{array}{l}\text { High restrained } \\
\text { high impulsive }\end{array}$ & $\begin{array}{l}\text { High restrained } \\
\text { low impulsive }\end{array}$ & $\begin{array}{l}\text { Low restrained } \\
\text { high impulsive }\end{array}$ & $\begin{array}{l}\text { Low restrained } \\
\text { low impulsive }\end{array}$ & $F(3,59)$ \\
\hline & $N=12$ & $N=12$ & $N=20$ & $N=19$ & \\
\hline$\overline{\text { Age }}$ & $18.8(0.9)$ & $18.8(0.9)$ & $19.3(1.3)$ & $19.2(1.7)$ & $<1$ \\
\hline BMI & $24.5(2.4)_{a}$ & $23.5(2.8)_{a}$ & $21.8(2.0)_{\mathrm{b}}$ & $21.1(2.1)_{b}$ & $6.9^{*}$ \\
\hline RS & $20.4(3.8)_{a}$ & $19.1(3.8)_{a}$ & $7.7(3.6)_{b}$ & $7.5(3.4)_{\mathrm{b}}$ & $55.2^{*}$ \\
\hline SSRT & $204(34.9)_{\mathrm{a}}$ & $151(15.8)_{\mathrm{b}}$ & $205(21.0)_{a}$ & $147(16.2)_{\mathrm{b}}$ & $33.4^{*}$ \\
\hline
\end{tabular}

$* p<0.001$.

Means not sharing similar subscripts within a row differ at $p<0.05$. 
variable for the HR-HI participants separately (hypothesis a) showed a significant main effect for condition in the HR-HI group, $F(2,22)=5.8, p=0.01$. Planned contrasts within the HR-HI group showed significant differences in caloric intake between the Exposure and Preload conditions, $F(1,11)=6.3, p=0.029$, and between the Control and Preload conditions, $F(1,11)=14.5$, $p=0.003$. No difference between the Exposure and Control conditions emerged, $F(1,11)<1$. Fig. 1 shows that HR-HI participants ate significantly more in the Exposure and Control conditions than in the Preload condition.

The repeated measures ANOVA for the HR-LI participants (hypothesis b) showed no main effect for condition, $F(2,22)<1$, and no significant within-subjects contrast, $F(1,11)<1$, demonstrating that, contrary to the hypothesis, the HR-LI group ate comparable amounts in all conditions.

To test the c-part of the hypothesis, a one-way repeated measures ANOVA with condition as the repeated measures factor and caloric intake as the dependent variable for the LR-LI participants was done. No main effect for condition emerged, $F(2,36)=2.3$, NS, showing that the eating pattern of the LR-LI group is the same as the eating pattern of the HR-LI group. As predicted, the caloric intake of the LR-LI participants was comparable in all conditions. The final part of the hypothesis states that, as is the case for LR-LI participants, also LR-HI participants will not show differences in intake in the three conditions. The repeated measures ANOVA for the LR-HI participants showed no main effect for condition, $F(2,38)<1$, NS. These participants also showed no differential responding over conditions, whereas they did show an eating pattern identical to that of the HR-LI and the LR-LI participants.

It was further tested how dietary restraint, impulsivity and food intake were related as a function of the three experimental conditions by calculating Pearson P-M correlations. For the whole group, a significant correlation between Restraint and Caloric intake after exposure was found, $r=0.25, p<0.05$, but other correlations were not significant. We then divided the sample in high- and low-impulsive participants (median-split on the SSRT) and calculated correlations between dietary restraint and caloric intake as a function of the three experimental conditions for both subsamples separately. Table 2 shows significant correlations between dietary restraint and caloric intake after food cue exposure, as well as after a preload and in the control condition, for the high-impulsive participants only. Thus, consistent with our hypothesis, dietary restraint showed a positive correlation to

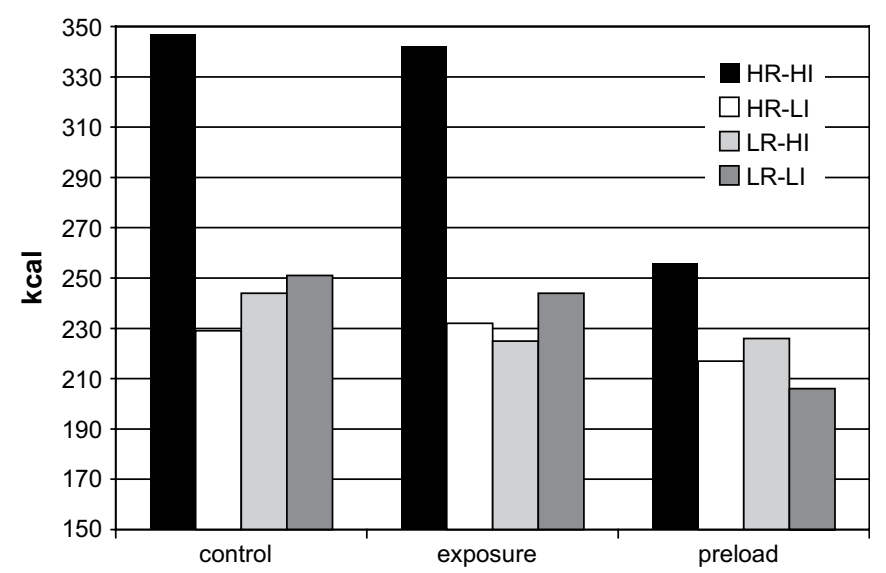

Fig. 1. Food intake after tasty food exposure (exposure), consumption of a preload (preload) and a control manipulation (control) for participants that were either high or low in eating restraint and impulsivity. HR-HI: high restrained and high impulsive, HRLI: high restrained and low impulsive, LR-HI: low restrained and high impulsive, LR-LI: low restrained and low impulsive. $\mathrm{kcal}=$ kilocalories consumed.
Table 2

Pearson P-M correlations between food intake (consumed kilocalories) and restraint (RS score), for high- and low-impulsive participants.

\begin{tabular}{lll}
\hline & & Restraint \\
\hline Low impulsive $(n=31)$ & Exposure & 0.04 \\
& Preload & 0.01 \\
& Control & 0.03 \\
High impulsive $(n=32)$ & Exposure & $0.30^{*}$ \\
& Preload & $0.46^{* *}$ \\
& Control & $0.34^{*}$ \\
\hline
\end{tabular}

${ }^{*} p<0.05,{ }^{* *} p<0.005$, one-tailed.

caloric intake in all conditions but only for the high-impulsive participants, indicating that impulsivity moderates the relationship between restraint and food intake.

\section{Discussion}

The present study shows that overeating follows from an interaction between restraint and impulsivity; high-restrained eaters only overate if they were also high impulsive. It might be concluded from these data that being restrained in and of itself is not a determinant of overeating. Being eating-restrained bears the risk of overeating only in case of a coexisting impulsivity.

Likewise, being restrained is not a determinant of 'undereating' or caloric restriction. Contrary to what was expected, the highrestrained participants that were low impulsive did not consume fewer calories than those with lower restraint scores, confirming that the restraint scale is not a valid measure of caloric restriction (Stice et al., 2004, 2006; Williamson et al., 2007). These data are in line with the view that high scores on restraint scales do not refer to actual restrictive dieting (Stice et al., 2006). The present data additionally show that in particular the high-restrained eaters who are at the same time highly impulsive show disinhibition of food intake under a variety of conditions like being exposed to tasty foods.

Impulsivity is usually broadly defined as a tendency to think, control and plan insufficiently and it is considered a multidimensional construct (Guerrieri, 2008; Whiteside \& Lynam, 2001). The kind of impulsivity that was measured with the present stop-signal task explicitly refers to weak response inhibition. Apart from response inhibition, it has also been argued and found that increased reward sensitivity and the inability to delay gratification are related to overeating (Davis et al., 2007; Guerrieri, Nederkoorn, \& Jansen, 2008; Reynolds \& Schiffbauer, 2005). It would be of interest to know whether the overeating of high-restrained eaters after a food challenge is exclusively related to decreased response inhibition, like we measured in the present study, or whether interactions between restraint and reward sensitivity or the inability to delay gratification will result in identical eating patterns.

As expected, the high-impulsive high-restrained participants did overeat after being exposed to the intense smelling of tasty foods, but a counterintuitive and a typical finding in the present study is that the high-restrained high-impulsive participants also overate in the control condition, and not in the preload condition. The classic counter-regulation phenomenon of high-restrained eaters is exactly the other way around: high-restrained eaters eat more after a preload than without one, (e.g., Herman \& Mack, 1975; Hibscher \& Herman, 1977; Ruderman, 1986). Their overeating in the current control condition might unintentionally have been induced by the nature of the questionnaire that we used as time filler in the control condition. Participants completed Zuckerman's sensation seeking scale during the $10 \mathrm{~min}$ before the taste test. This might have been working as an impulsivity induction; the scale asks how 
much the participant likes to be involved in all kinds of impulsive and disinhibitive behaviors. Considering that impulsivity could be primed by the mere reading of scripts on impulsivity (Guerrieri, Nederkoorn, Schrooten, et al., 2008) and the mere priming of lack of control thoughts (Rotenberg et al., 2005) both of which led to overeating, completing the sensation seeking scale in the present study likewise might have acted as an impulsivity or disinhibition prime. This might explain the overeating of the high-restrained high-impulsive participants in the control condition and the present data would suggest that in particular the high-restrained high-impulsive participants are vulnerable to this kind of impulsivity inductions.

Apart from the control manipulation being an obvious limitation of this study, because of its possible impulsivity inducing effects, another possible limitation is the use of a within-subjects design that might have induced learning effects. An advantage of a withinsubjects design is that people are their own control group, which is useful in eating behavior studies because of the large range in calorie consumption between people. But the overeating of the highrestrained high-impulsive participants in the control condition might be related to the use of a within-subjects design, for this design implies that $1 / 3$ of the participants were already exposed twice to a food condition (preload and exposure) before participating in the control condition, and $1 / 3$ were exposed once to a food condition (preload or exposure) during an earlier session. These participants might have learned to associate the laboratory with food intake, and might have anticipated eating, which in turn might have led the sensitive participants into overeating in the control condition. In future research it is important to include a control group that does not prime people for either food salience or impulsivity.

Although completing the sensation seeking questionnaire and/ or associative learning between lab and food intake might explain the higher intake in the control condition, it still remains a puzzle to us why the high-restrained high-impulsive participants did not overeat after a preload. The present preload contained $280 \mathrm{kcal}$, which is a lot for an appetizer but not excessive, and which is quite comparable to preloads that we used in other experiments (e.g., Jansen, Merckelbach, Oosterlaan, Tuiten, \& van den Hout, 1988; Jansen, Oosterlaan, et al., 1988). If the preload decreased hunger, these findings are in line with some recent data of our lab showing that high-restrained high-impulsive undergraduates bought significantly more high-caloric foods in a virtual supermarket compared to the low-impulsive undergraduates, but only when they were hungry (Nederkoorn et al., 2008). It would be of interest for future studies to test whether post-appetizer disinhibition reflects a state by trait interaction between impulsivity, restraint and hunger.

Earlier findings show that the induction of impulsivity makes healthy people more vulnerable to overeating, especially in interaction with restraint, and the other way around it has been shown that the priming of inhibition and control led to more self-control and decreased food intake (Guerrieri, Nederkoorn, Schrooten, et al., 2008; Rotenberg et al., 2005). It would be a rewarding enterprise to further study ways that promote inhibition or self-control in otherwise impulsive people, not only to find out under which conditions high-restrained high-impulsive eaters do and do not overeat. Dieting will be much easier and probably much more successful for high-restrained eaters when they are less impulsive, making this kind of research extremely useful for the development of interventions that reduce impulsivity in people who suffer from impulsive overeating.

\section{Acknowledgements}

Marike Jager and Joyce Groenveld are thanked for their help during the experiment.

\section{References}

Barkley, R. A. (1997). Behavioral inhibition, sustained attention, and executive functions: constructing a unifying theory of ADHD. Psychological Bulletin, 121, $65-94$

Davis, C., Patte, K., Levitan, R., Reid, C., Tweed, S., \& Curtis, C. (2007). From motivation to behaviour: a model of reward sensitivity, overeating, and food preferences in the risk profile for obesity. Appetite, 48, 12-19.

Dritschel, B., Cooper, P. J., \& Charnock, D. (1993). A problematic counter-regulation experiment: implications for the link between dietary restraint and overeating. International Journal of Eating Disorders, 13, 297-304.

Fedoroff, I. C., Polivy, J., \& Herman, C. P. (1997). The effect of pre-exposure to food cues on the eating behavior of restrained and unrestrained eaters. Appetite, 28, 33-47.

Feij, J. A., \& van Zuilen, R. W. (1984). Spanningsbehoeftelijst (Sensation seeking scale). Lisse: Swets and Zeitlinger.

Guerrieri, R. (2008). Resisting temptation: the effect of an impulsive personality and a toxic environment on overeating. Ph.D. Dissertation, Maastricht University.

Guerrieri, R., Nederkoorn, Ch, \& Jansen, A. (2007). How impulsiveness and variety influence food intake in a sample of healthy women. Appetite, 48, 119-122.

Guerrieri, R., Nederkoorn, C., \& Jansen, A. (2008). The interaction between impulsivity and a varied food environment: its influence on food intake and overweight. International Journal of Obesity, 32, 708-714.

Guerrieri, R., Nederkoorn, C., Schrooten, M., Martijn, C., \& Jansen, A. (2008). Inducing impulsivity leads restrained eaters into overeating whereas current dieters stick to their diet, submitted for publication.

Guerrieri, R., Nederkoorn, Ch., Stankiewicz, K., Alberts, H., Geschwind, N., Martijn, C., et al. (2007). The influence of trait and induced state impulsivity on food intake in normal-weight healthy women. Appetite, 49, 66-73.

Herman, C. P., \& Mack, D. (1975). Restrained and unrestrained eating. Journal of Personality, 43, 647-660.

Herman, C. P., \& Polivy, J. (1980). Restrained eating. In A. J. Stunkard (Ed.), Obesity (pp. 208-225). Philadelphia: Saunders.

Hibscher, J. A., \& Herman, C. P. (1977). Obesity, dieting, and the expression of 'obese' characteristics. Journal of Comparative Physiology and Psychology, 91, 374-380.

Jansen, A. (1998). A learning model of binge eating: cue reactivity and cue exposure. Behaviour Research and Therapy, 36, 257-272.

Jansen, A., \& van den Hout, M. (1991). On being led into temptation: 'counterregulation' of dieters after smelling a 'preload'. Addictive Behaviors, 5, 247-253.

Jansen, A., Louwerse, E., Leemans, N., \& Schouten, E. (1998). Self-esteem as a better predictor of restrained eaters' food intake than attributional style and disinhibition tendency. European Journal of Personality, 12, 43-56.

Jansen, A., Merckelbach, H., Oosterlaan, J., Tuiten, A., \& van den Hout, M. (1988). Cognitions and self-talk during food intake of restrained and unrestrained eaters. Behaviour Research and Therapy, 26, 393-398.

Jansen, A., Oosterlaan, J., Merckelbach, H., \& van den Hout, M. (1988). Non-regulation of food intake in restrained, emotional and external eaters. Journal of Psychopathology and Behavioral Assessment, 10, 345-354.

Jansen, A., Theunissen, N., Slechten, K., Nederkoorn, C., Mulkens, S., \& Roefs, A. (2003). Overweight children overeat after exposure to food cues. Eating Behaviors, 4, 197-209.

Logan, G. D., Schachar, R. J., \& Tannock, R. (1997). Impulsivity and inhibitory control. Psychological Science, 8, 60-64

Nederkoorn, C., Braet, C., van Eijs, Y., Tanghe, A., \& Jansen, A. (2006). Why obese children cannot resist food: the role of impulsivity. Eating Behaviors, 7, 315-322.

Nederkoorn, C., van Eys, Y., \& Jansen, A. (2004). Restrained eaters act on impulse. Personality and Individual Differences, 37, 1651-1658.

Nederkoorn, C., Guerrieri, R., Roefs, A., \& Jansen, A. (2008). Effects of impulsivity on food purchase and weight gain over time (BFDG abstract). Appetite, in press, http://dx.doi.org/10.1016/j.appet.2008.05.007.

Nederkoorn, C., \& Jansen, A. (2002). Cue reactivity and regulation of food intake. Eating Behaviors, 3, 61-72.

Nederkoorn, C., Jansen, E., Mulkens, S., \& Jansen, A. (2007). Impulsivity predicts treatment outcome in obese children. Behaviour Research and Therapy, 45, 1071-1075.

Nederkoorn, C., Smulders, F. T. Y., Havermans, R. C., Roefs, A., \& Jansen, A. (2006). Impulsivity in obese women. Appetite, 47, 253-256.

Nichols, S. L., \& Waschbusch, D. A. (2004). A review of the validity of laboratory cognitive tasks used to assess symptoms of ADHD. Child Psychiatry and Human Development, 34, 297-315.

Reynolds, B., \& Schiffbauer, R. (2005). Delay of gratification and delay discounting: a unifying feedback model of delay-related impulsive behavior. The Psychological Record, 55, 439-460.

Rogers, P. J., \& Hill, A. J. (1989). Breakdown of dietary restraint following mere exposure to food stimuli: interrelationships between restraint, hunger, salivation, and food intake. Addictive Behaviors, 14, 387-397.

Rotenberg, K. J., Lancaster, C., Marsden, J., Pryce, S., Williams, J., \& Lattimore, P. (2005). Effects of priming thoughts about control on anxiety and food intake as moderated by dietary restraint. Appetite, 44, 235-241.

Ruderman, A. J. (1986). Dietary restraint: a theoretical and empirical review. Psychological Bulletin, 99, 247-262.

Stice, E., Fisher, M., \& Lowe, M. R. (2004). Are dietary restraint scales valid measures of acute dietary restriction? Unobtrusive observational data suggest not. Psychological Assessment, 16, 51-59. 
Stice, E., Presnell, K., Lowe, M. R., \& Burton, E. (2006). Validity of dietary restraint scales: reply to van Strien, et al. (2006). Psychological Assessment, 18, 95-99.

Wardle, J. (1986). The assessment of restrained eating. Behaviour Research and Therapy, 24, 213-215.

Wardle, J., \& Beales, S. (1987). Restraint and food intake: an experimental study of eating patterns in the laboratory and in normal life. Behaviour Research and Therapy, 25, 179-185.
Whiteside, S. P., \& Lynam, D. R. (2001). The five factor model and impulsivity: using a structural model of personality to understand impulsivity. Personality and Individual Differences, 30, 669-689.

Williamson, D. A., Martin, C. K., York-Crowe, E., Anton, S. D., Redman, L. M., Han, H. et al. (2007). Measurement of dietary restraint: validity tests of four questionnaires. Appetite, 48, 183-192.

Zuckerman, M. (1994). Behavioral expressions and biosocial bases of sensation seeking. Cambridge: Cambridge University Press. 